\title{
Assessment of the incidence and preventability of adverse events in hospitals: an integrative review
}

\author{
Avaliação da incidência e evitabilidade de \\ eventos adversos em hospitais: revisão integrativa \\ Evaluación de la incidencia y de la posibilidad de evitar \\ eventos adversos en hospitales: una revisión integradora
}

\section{Ariane Cristina Barboza Zanettia Carmen Silvia Gabriel ${ }^{a}$ Bruna Moreno Dias ${ }^{a}$ Andrea Bernardes ${ }^{\mathrm{a}}$ André Almeida de Moura ${ }^{a}$ Andréia Boldrini Gabriel ${ }^{\mathrm{a}}$ Antônio José de Lima Júnior ${ }^{\mathrm{a}}$}

How to cite this article: Zanetti ACB, Gabriel CS, Dias BM, Bernardes A, Moura AA, Gabriel AB, Lima Júnior AJ. Assessment of the incidence and preventability of adverse events in hospitals: an integrative review. Rev Gaúcha Enferm. 2020;41:e20190364. doi: https://doi.org/10.1590/19831447.2020.20190364 aniversidade de São Paulo (USP), Escola de Enfermagem de Ribeirão Preto, Departamento de Enfermagem Geral e Especializada. Ribeirão Preto, São Paulo, Brasil.

\section{ABSTRACT}

Objective: To highlight the scientific production related to the use of the retrospective chart review methods to assess the incidence and preventability of adverse events in hospitals.

Method: An integrative review in the MEDLINE, LILACS, SCOPUS, Web of Science and EMBASE databases conducted in May 2019 with the following guiding question: What is known about the retrospective chart review methods to assess the incidence and preventability of adverse events in hospitals? Subsequently, the categorization, synthesis, and classification of the evidence levels of the included publications were performed.

Results: In the 13 selected studies, the instruments adopted to assess the occurrence of adverse events were the Harvard Medical Practice Study, the Canadian Adverse Event Study, the Quality in Australian Health Care Study, and the Global Trigger Tool. Incidence ranged from 5.7 to $14.2 \%$, while preventability ranged from 31 to $83 \%$.

Conclusion: Differences in incidence and preventability were found, showing different results in the quality of care provided, the information registered in medical records, the screening criteria used, and the assessments of the reviewers.

Keywords: Patient safety. Medical errors. Hospitals. Retrospective studies.

\section{RESUMO}

Objetivo: Evidenciar a produção científica relacionada à adoção de métodos de revisão retrospectiva de prontuários para avaliação da incidência e evitabilidade de eventos adversos em hospitais.

Método: Revisão integrativa nas bases de dados MEDLINE, LLLACS, SCOPUS, Web of Science e EMBASE, realizada em maio de 2019, tendo como questão norteadora: qual é o conhecimento sobre a adoção de métodos de revisão retrospectiva de prontuários de pacientes internados para avaliação da incidência e evitabilidade de eventos adversos em hospitais? Após, executou-se categorização, síntese e classificação dos níveis de evidência das publicações incluídas.

Resultados: Dentre 13 estudos selecionados, os instrumentos adotados para avaliação da ocorrência de eventos adversos foram 0 Harvard Medical Practice Study, Canadian Adverse Event Study, Quality in Australian Health Care Study e Global Trigger Tool. A variação da incidência foi de 5,7 a 14,2\%, enquanto da evitabilidade foi de 31 a $83 \%$.

Conclusão: Verificaram-se diferenças na incidência e evitabilidade, havendo heterogeneidade na qualidade do cuidado prestado, informações registradas nos prontuários, critérios de rastreamento utilizados e avaliações dos revisores.

Palavras-chave: Segurança do paciente. Erros médicos. Hospitais. Estudos retrospectivos.

\section{RESUMEN}

Objetivo: Destacar la producción científica relacionada con la adopción de la revisión retrospectiva de registros médicos para evaluar la incidencia y la posibilidad de evitar eventos adversos en los hospitales.

Método: Revisión integradora en las bases de datos MEDLINE, LLLACS, SCOPUS, Web of Science y EMBASE realizada en mayo de 2019 con la siguiente pregunta guía: ¿Qué se conoce sobre la adopción de métodos de revisión retrospectiva de registros de pacientes internados para evaluar la incidencia y la posibilidad de evitar eventos adversos en los hospitales? Seguidamente se realizó la categorización, síntesis y clasificación de los niveles de evidencia de las publicaciones incluidas.

Resultados: Entre 13 estudios seleccionados, los instrumentos adoptados para evaluar la presencia de eventos adversos fueron el Harvard Medical Practice Study, el Canadian Adverse Event Study, el Quality in Australian Health Care Study y la Global Trigger Tool. La incidencia varió de 5,7 a 14,2\%, mientras que la posibilidad de evitar eventos adversos varió de 31 a $83 \%$.

Conclusión: Se encontraron diferencias en la incidencia y la posibilidad de evitar eventos adversos, con heterogeneidad en la calidad de la atención brindada, la información registrada en las historias clínicas, los criterios de detección utilizados, y las evaluaciones de los revisores. Palabras clave: Seguridad del paciente. Errores médicos. Hospitales. Estudios retrospectivos. 


\section{INTRODUCTION}

Adverse Events (AEs) compromise, on average, 10\% of the hospital admissions, and up to $75 \%$ of these errors are preventable, which is why they are one of the biggest challenges for improving quality in the health area ${ }^{(1-2)}$. According to the International Classification for Patient Safety, which aimed to organize the concepts and definitions of patient safety, an AE is an unintentional injury or harm that results in temporary or permanent disability or dysfunction, and/ or increases the length of hospital stay or causes death due to the health care provided, with no link to the patient's underlying disease process ${ }^{(3-4)}$. In this sense, patient safety is interpreted as the conduct to reduce the risk of unnecessary harms associated with health care to an acceptable minimum, with the aim of mitigating the incidence of AEs and increase the probability of intercepting them at the time of the occurrence $e^{(5-6)}$.

AEs are preventable when they are derived from errors. In general, these sudden events do not cause serious injury/ harms to patients; however, permanent disability and death occur in certain situations. The identification of the true extent of these problems represents a unique opportunity for strategies aimed at ensuring patient safety ${ }^{(2,7)}$.

In this scenario, the identification of AEs in the health services is supported by multiple detection tools, such as: review of the medical record, review of mortality and morbidity rates, analysis of voluntary notification systems, direct observation, and evaluation of complaint systems. There is no gold standard for the identification of AEs, since each of the available methods to determine the proportion of these events has some methodological weakness. In this sense, the scientific literature confirms that, despite the limitations, retrospective review studies of medical records provide valid resources for assessing AEs in hospital setting ${ }^{(8-9)}$. It is noted that the underreporting evidenced in the research studies which use notification databases can lead to the understanding that the medical record review methods are more effective in detecting events, as described in a study conducted in the United Kingdom, which estimated that only $5 \%$ of the incidents are properly reported ${ }^{(10)}$.

A systematic review on the topic published in 2005 identified studies that address the AEs in hospital organizations located in the USA, Australia, New Zealand, France, England, Denmark, and Canada, which, grouped, evaluated a total of 92,063 medical records and found an AE incidence rate that ranged between $2.9 \%$ and $16.6 \%$. Among all the
AEs, 38\% were related to surgical procedures and $19 \%$ to medications ${ }^{(11)}$.

The identification and analysis of AEs are, therefore, capable of promoting a deeper and adequate understanding of the susceptibility to failures in the health care systems. Once it is possible to evaluate and measure the AEs, strategies aimed at improving the quality of health care ${ }^{(12)}$ become feasible and achievable. Given the relevance of the topic for patient safety, there is a need to update, through a literature review, the knowledge produced in order to indicate tools applicable to the hospital context for the detection of AEs. Thus, the study was guided by the following research question: What is the knowledge produced about the adoption of retrospective chart review methods to assess the incidence and preventability of AEs in hospitals? To answer this question, the objective was to highlight the scientific production related to the adoption of retrospective chart review methods to assess the incidence and preventability of AEs in hospitals.

\section{METHOD}

The methodological framework adopted was the integrative literature review, which was structured in six stages: definition of the problem and of the objective of the study; adoption of inclusion and exclusion criteria for the publications and literature search; categorization of the primary studies; analysis of the studies included in the integrative review; interpretation of the results; and presentation of the review by synthesizing the knowledge produced ${ }^{(13-15)}$.

Thus, the following guiding question was established: What is the knowledge produced regarding the adoption of retrospective chart review methods to assess the incidence and preventability of AEs in hospitals? It is important to note that the guiding question was created using the PICO strategy, acronym for Population (or Problem), Intervention, Comparison, and Outcomes ${ }^{(16)}$.

The searches were performed during the month of May 2019, in the following databases: MEDLINE through the PubMed portal; Latin American and Caribbean Health Sciences Literature (Literatura Latino-americana e do Caribe em Ciências da Saúde, LILACS); SCOPUS; Web of Science; and EMBASE. Access to the databases was through the Integrated Library System of the University of São Paulo (Sistema Integrado de Bibliotecas da Universidade de São Paulo, SIBiUSP). The following controlled keywords were used: "Medical errors/Erros médicos", "Hospitals/Hospitais" and "Retrospective studies/Estudos retrospectivos", as well as the uncontrolled keyword "Adverse events/Eventos adversos". The keywords of 
the controlled vocabularies in the databases were established in accordance with the Medical Subject Headings (MeSH), with Emtree (controlled vocabulary from EMBASE), and with the Health Sciences Descriptors (Descritores em Ciências da Saúde, DeCS). It should be noted that the Boolean operator "AND" was used to combine the keywords.

The inclusion criteria stipulated were primary articles, available in full, and published in English, Spanish and Portuguese from September 2004 to April 2019. The choice of this period of publication is justified due to the existence of a systematic review ${ }^{(11)}$ published in 2005 which quantified, based on retrospective chart review studies, AEs in hospitals by analyzing texts published until August 2004. The excluded papers were reviews, theses, dissertations and editorials. It is important to highlight that, to reduce the risk of bias in the inclusion of the studies, two reviewers were responsible for checking and validating the selection.

Subsequently, for the analysis, categorization, and synthesis of the included publications, the scientific articles were reviewed through a validated instrument that includes identification data of the original article, the profile and methodological rigor of the search, the interventions verified, and the main outcomes ${ }^{(17)}$. Thus, in order to compile the information in the articles and to establish thematic categories, the information relevant for the review was categorized and grouped in synoptic tables. For the initial description and summary of the data, simple descriptive statistics were used and, to complement this method, the levels of evidence of each article were classified ${ }^{(18)}$.

\section{Q RESULTS}

After identifying and analyzing 754 publications, 13 manuscripts were included, which were related to the studies used in the retrospective chart review to assess AEs in hospitals. The selection process and the number of publications obtained in each stage of the screening are detailed in the flowchart shown in Figure 1.

Among the studies included in this review, seven were conducted in Europe (three in Spain, one in Portugal, one in Ireland, one in the Netherlands, and one in England), two in South America (one in Brazil and one in Chile), two in Asia (one in Iran and one in Palestine), one in Africa (Tunisia) and one both in Asia and Africa, concomitantly (in Egypt, Jordan, Kenya, Morocco, South Africa, Sudan, Tunisia, and Yemen). Regarding the populations of hospitalized patients, the size and particularities of the samples varied, which shows the heterogeneity of the investigated locations and contexts.

Regarding the distribution of the articles in the years of publication examined, the following proportion was observed: $2007(n=1), 2008(n=1), 2009(n=2), 2010(n=1)$, $2012(n=2), 2013(n=1), 2014(n=3), 2015(n=1)$, and $2017(n=1)$. There was a higher number of publications in 2009, 2012 and 2014, which represented 53.8\% of the sample. In addition, among the manuscripts explored, it was found that most of the research studies $(n=12)$ were supported by university institutions and showed diversity regarding the hospital organizations chosen for study sites, such as university, public, private, general, and specific hospitals.

Regarding the type of scientific journal in which the manuscripts were disseminated, it was found that eight articles were published in journals linked to the quality of health care, two in journals in the sphere of medical sciences, and three in journals specialized in other areas of Health Sciences. The following was observed regarding the methodological design and level of evidence of the studies: six retrospective studies with a quantitative approach, with evidence level VI; and seven retrospective cohort studies, with evidence level IV. Chart 1 shows the synthesis of the manuscripts chosen for analysis, which are identified in accordance to the number shown in the consecutive references of the review. 


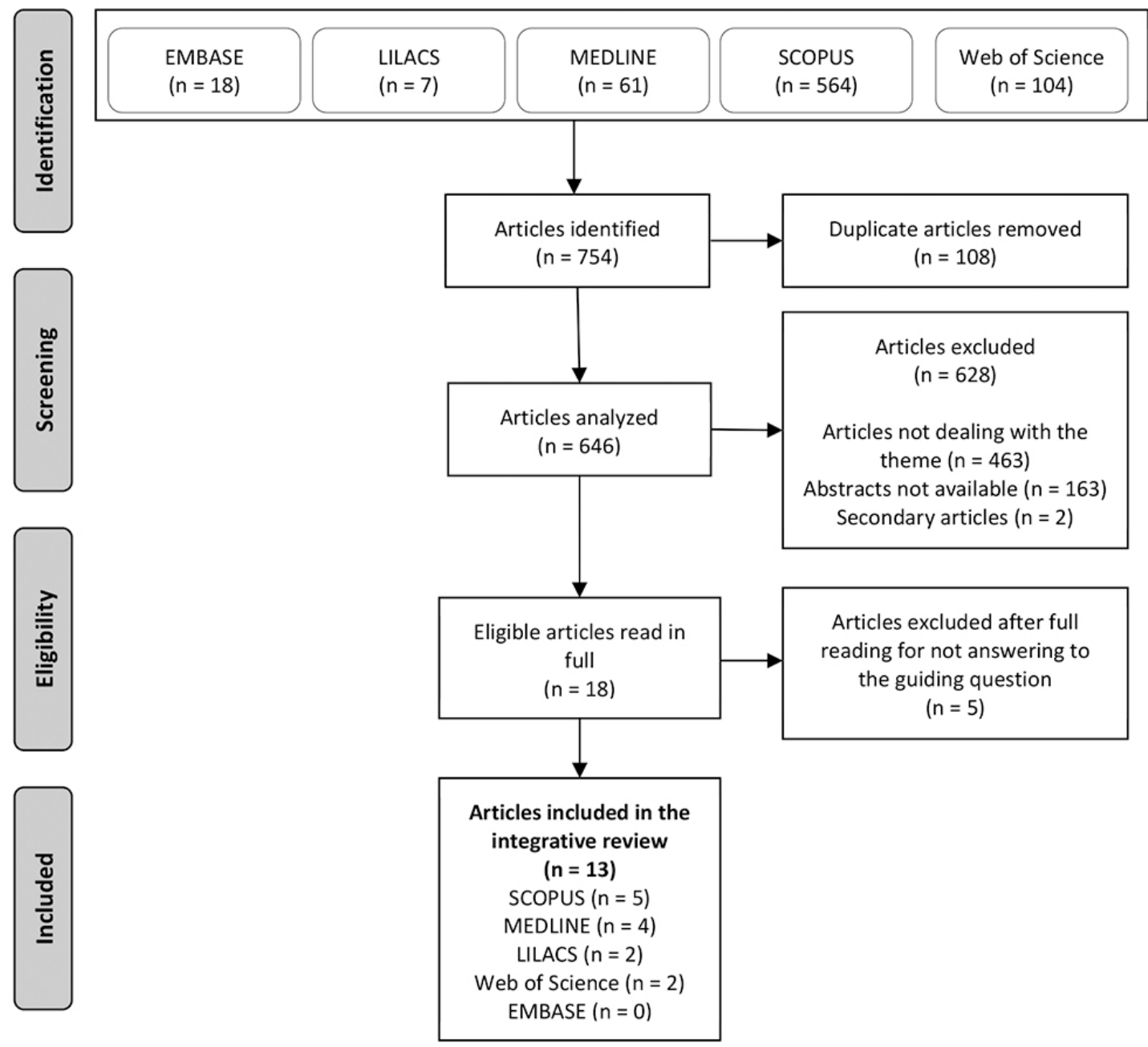

Figure 1 - Flowchart of the article selection process for the integrative review Source: Research data, 2019.

\begin{tabular}{|c|c|c|c|}
\hline $\begin{array}{c}\text { Study/ } \\
\text { Evidence level }\end{array}$ & $\begin{array}{c}\text { Country, year of publication, } \\
\text { number of charts sampled, } \\
\text { and period of the retrospective } \\
\text { review }\end{array}$ & $\begin{array}{l}\text { Instruments to assess AEs in } \\
\text { hospitals }\end{array}$ & Results \\
\hline (19) / VI & $\begin{array}{c}\text { England, } 2007 \text { - 1,006 medical records } \\
\text { of hospitalized patients between } \\
\text { January and May } 2004\end{array}$ & $\begin{array}{l}\text { Assessment instruments } \\
\text { developed by the Harvard } \\
\text { Medical Practice Study (HMPS) }\end{array}$ & $\begin{array}{c}\text { AE incidence }=8.7 \% \\
\text { Preventable AEs }=31 \%\end{array}$ \\
\hline (20) / IV & $\begin{array}{c}\text { Spain, } 2008-5,624 \text { records of patients } \\
\text { discharged between June } 4^{\text {th }} \text { and } \\
\text { June } 10^{\text {th }}, 2005\end{array}$ & $\begin{array}{l}\text { Assessment instruments } \\
\text { developed by the HMPS }\end{array}$ & $\begin{array}{l}\text { AE incidence }=8.4 \% \\
\text { Preventable } \\
\text { AEs }=42.6 \%\end{array}$ \\
\hline (21) / IV & $\begin{array}{c}\text { Brazil, } 2009 \text { - 1,103 medical records of } \\
\text { patients admitted during } 2003\end{array}$ & $\begin{array}{c}\text { Assessment instruments } \\
\text { developed by the Canadian } \\
\text { Adverse Events Study (CAES)* }\end{array}$ & $\begin{array}{c}\text { AE incidence }=7.6 \% \\
\text { Preventable } \\
\text { AEs }=66.7 \%\end{array}$ \\
\hline
\end{tabular}

Chart 1 - Summary chart of the articles included in the integrative literature review 


\begin{tabular}{|c|c|c|c|}
\hline $\begin{array}{c}\text { Study/ } \\
\text { Evidence level }\end{array}$ & $\begin{array}{c}\text { Country, year of publication, } \\
\text { number of charts sampled, } \\
\text { and period of the retrospective } \\
\text { review }\end{array}$ & $\begin{array}{l}\text { Instruments to assess AEs in } \\
\text { hospitals }\end{array}$ & Results \\
\hline (22) / VI & $\begin{array}{c}\text { Netherlands, } 2009 \text { - 7,926 records of } \\
\text { patients admitted in } 2004\end{array}$ & $\begin{array}{l}\text { Assessment instruments } \\
\text { developed by the CAES* }\end{array}$ & $\begin{array}{c}\text { AE incidence }=5.7 \% \\
\text { Preventable } \\
\text { AEs }=39.6 \%\end{array}$ \\
\hline (23) / IV & $\begin{array}{c}\text { Tunisia, } 2010 \text { - } 620 \text { medical records of } \\
\text { patients admitted in } 2005\end{array}$ & $\begin{array}{l}\text { Assessment instruments } \\
\text { developed by the HMPS }\end{array}$ & $\begin{array}{c}\text { AE incidence }=10 \% \\
\text { Preventable AEs }=60 \%\end{array}$ \\
\hline (24) / IV & $\begin{array}{l}\text { Spain, } 2012-1,143 \text { medical } \\
\text { records of patients discharged } \\
\text { between November } 5^{\text {th }} \text { and } \\
\quad \text { November } 19^{\text {th }}, 2006\end{array}$ & $\begin{array}{l}\text { Assessment instruments } \\
\text { developed by the HMPS }\end{array}$ & $\begin{array}{c}\text { AE incidence }=6.8 \% \\
\text { Preventable } \\
\text { AEs }=63.3 \%\end{array}$ \\
\hline (25) / VI & $\begin{array}{c}\text { Egypt, Jordan, Kenya, Morocco, } \\
\text { South Africa, Sudan, Tunisia, and } \\
\text { Yemen, } 2012 \text { - 15,548 medical records } \\
\text { of patients admitted in } 2005\end{array}$ & $\begin{array}{c}\text { Assessment instruments } \\
\text { developed by the Quality } \\
\text { in Australian Health Care } \\
\text { Study (QAHCS)* }\end{array}$ & $\begin{array}{c}\text { AE incidence }=8.2 \% \\
\text { Preventable AEs }=83 \%\end{array}$ \\
\hline (26) / VI & $\begin{array}{c}\text { Palestine, } 2013 \text { - } 640 \text { medical records } \\
\text { of patients discharged between May } \\
\text { and August } 2009\end{array}$ & $\begin{array}{c}\text { Global Trigger Tool proposed } \\
\text { by the Institute for Healthcare } \\
\text { Improvement (IHI-GTT) }\end{array}$ & $\begin{array}{c}\text { AE incidence }=14.2 \% \\
\text { Preventable } \\
\text { AEs }=59.3 \%\end{array}$ \\
\hline (27) / IV & $\begin{array}{l}\text { Chile, } 2014 \text { - } 500 \text { records of patients } \\
\text { discharged between January } 16^{\text {th }} \text { and } \\
\text { January } 31^{\text {st }}, 2012\end{array}$ & $\begin{array}{l}\text { Assessment instruments } \\
\text { developed by the HMPS }\end{array}$ & $\begin{array}{c}\text { AE incidence }=6.2 \% \\
\text { Preventable } \\
\text { AEs }=67.6 \%\end{array}$ \\
\hline (28) / IV & $\begin{array}{c}\text { Spain, } 2014-4,790 \text { medical records of } \\
\text { patients discharged in } 2004\end{array}$ & $\begin{array}{c}\text { Assessment instruments } \\
\text { created based on HMPS, CAES } \\
\text { and QAHCS }\end{array}$ & $\begin{array}{c}\text { AE incidence }=7.4 \% \\
\text { Preventable } \\
\text { AEs }=43.5 \%\end{array}$ \\
\hline (29) / IV & $\begin{array}{l}\text { Portugal, } 2014 \text { - 1,669 medical } \\
\text { records of patients admitted between } \\
\text { January } 1^{\text {st }} \text { and December } 31^{\text {st }}, 2009\end{array}$ & $\begin{array}{c}\text { Assessment instruments } \\
\text { created based on HMPS, CAES } \\
\text { and QAHCS }\end{array}$ & $\begin{array}{c}\text { AE incidence }=11.1 \% \\
\text { Preventable } \\
\text { AEs }=53.2 \%\end{array}$ \\
\hline (30) / VI & $\begin{array}{c}\text { Iran, } 2015 \text { - 1,162 medical records of } \\
\text { patients admitted between April and } \\
\text { September } 2012\end{array}$ & $\begin{array}{c}\text { Assessment instruments } \\
\text { created based on HMPS, CAES } \\
\text { and QAHCS }\end{array}$ & $\begin{array}{c}\text { AE incidence }=7.3 \% \\
\text { Preventable } \\
\text { AEs }=34.3 \%\end{array}$ \\
\hline (31) / VI & $\begin{array}{l}\text { Ireland, } 2017 \text { - 1,574 medical records } \\
\text { of patients admitted in } 2009\end{array}$ & $\begin{array}{l}\text { Assessment instruments } \\
\text { developed by the CAES* }\end{array}$ & $\begin{array}{c}\text { AE incidence }=10.3 \% \\
\text { Preventable } \\
\text { AEs }=72.7 \%\end{array}$ \\
\hline
\end{tabular}

Chart 1 - Cont.

Source: Research data, 2019.

* Instruments created based on the HMPS retrospective chart review method. 
It should be noted that each of the studies included in this review had singularities regarding the inclusion and exclusion criteria, study sites, sample size, number of reviewers involved in the stages of assessing the incidence of AEs and criteria for screening potential AEs.

\section{DISCUSSION}

In order to analyze the publications included and to outline discussions about them, they were organized in two thematic categories: instruments to assess AEs in hospitals; and incidence, preventability, and main implications of AEs in hospitals.

\section{Instruments to assess AEs in hospitals}

Of the 13 studies, five explained the use of the retrospective chart review method developed by the Harvard Medical Practice Study (HMPS) ${ }^{(19-20,23-24,277}$. It is essential to emphasize that this research method was the precursor to other instruments used in a large part of the studies presented $(n=12)$.

In short, the HMPS was one of the pioneering studies in the context of assessing AEs, and analyzed a sample of 30,121 medical records of non-psychiatric patients admitted to 52 hospitals in the state of New York during 1984, revealing an AE incidence rate of $3.7 \%$. The HMPS retrospective chart review method was based on a two-stage sampling protocol. Initially, the medical records were tracked by trained nurses and other medical record analysts, based on defined criteria. Medical records with indication of potential AEs were selected, and two physicians previously trained to search for evidence of AEs and negligence performed independent reviews, classifying, according to a scale from zero to six (causality score), the level of confidence of the AE tracked. In cases where the level of confidence of the evaluators was greater than one, the injury caused was analyzed. The reviewers also assessed the evidence of negligence and indicated their level of confidence in that judgment ${ }^{(3,11)}$.

Another research ${ }^{(25)}$ used the AE assessment instruments from QAHCS, based on the HMPS protocol. However, based on the QAHCS, the research studies started to investigate preventable AEs and stopped investigating negligence. In this way, a preventable AE was defined as an error in the provision of care to the patient due to a failure of a specific individual or the system that failed to meet a certain requirement of good health practices. The QAHCS was initially carried out in Australia and analyzed a sample of 14,179 medical records of patients admitted to 28 acute care hospitals in 1992. The AE incidence rate found was $16.5 \%$ and the percentage of preventable AEs found was $50.3 \%{ }^{(11,32)}$.
To conduct the QAHCS, each participating hospital carried out a two-stage review of the medical records of their inpatients. The first stage involved the tracking of medical records by professional nurses, who searched for at least one of the 18 explicit criteria that indicated an AE. The medical records with the one or more of these criteria were sent to medical professionals for review, together with the first review form, containing the screening criteria, a summary of the relevant characteristics of the hospital admission and information on the quality of the medical record. The second stage required detailed and independent analyzes by two physicians to determine whether the potential AEs signaled by the nurses in the first phase had actually happened. For each medical record, the medical reviewers made a thorough analysis and filled out the second review form, evaluating the hospital admission index (hospitalization was object of study) in full, as well as any other relevant hospitalizations. The second stage of the chart review provided a brief clinical summary and a validation of the findings of the first stage, in addition to an analysis of the adequacy of medical records ${ }^{(32)}$.

A number of studies ${ }^{(21-22,31)}$ that used the AE assessment instruments designed by the CAES were also based on the HMPS protocol. The CAES investigated a sample of 3,745 medical records of patients admitted in 2000. The study included patients older than 18 years old who were admitted for more than 24 hours in hospitals in five Canadian provinces (university hospitals and community hospitals), excluding psychiatric and obstetric patients. The AE rate was $7.5 \%$, while the percentage of preventable AEs was $36.9 \%$. In that study, the review instruments were computerized and installed on portable computers, aiming at improving efficiency in data collection and the quality of information ${ }^{(11,33)}$.

The researchers responsible for the CAES carried out the chart review in two stages. In the first stage, nurses and other health professionals evaluated the selected medical records for the presence of one or more criteria for screening AEs, among 18 pre-established criteria, also registering the presence or absence of comorbidities. In the second stage, the physicians reviewed the medical records with a positive evaluation for at least one screening criterion and identified the existence of any unintentional injuries or complications. The injuries were classified according to the possibility of association with the patient's death, disability at the time of discharge, longer length of hospital stay, subsequent hospitalizations, and interventions without sequelae or outpatient treatment. Subsequently, using a 6-point causality scale, the medical reviewers determined the extent to which health care management was responsible for the injuries. Through an implicit judgment, the evaluators estimated the additional number of days of hospital stay directly attributable 
to the $A E$ and weighed the preventability of each $A E$ using a six-point scale ${ }^{(33)}$.

Other papers ${ }^{(28-30)}$ used combinations of the protocols created by HMPS, CAES and QAHCS and made adaptations to these instruments to assess AEs in hospitals.

Finally, one of the selected studies used the IHI-GTT to investigate the incidence of AEs in hospitals ${ }^{(26)}$. Attention is drawn to the fact that the research adapted the original version of the IHI-GTT for use in the hospitals surveyed, as there was a need to add specific triggers, modify others already stipulated and insert an additional step of reviewing medical records by a quality supervisor. The IHI-GTT was created in 2000 to offer a low cost alternative and without the need for using high technology to detect iatrogenic damage. It refers to the retrospective review of a random sample of medical records, using triggers (screening criteria), trying to distinguish potential AEs. Many hospitals adopt this tool to identify AEs, assess the level of harm, and determine whether such events are minimized over time as a result of quality improvement actions in institutions ${ }^{(34)}$.

The IHI-GTT uses specific methods to review medical records, presenting six modules designed to contemplate the AEs which occur in specific units and which aggregate several triggers inherent to the different services offered by hospital organizations, namely: general care, surgery, intensive care, medication, perinatal, and emergency. At first, the selected medical records are reviewed by two or three evaluators, usually nurses and pharmacists, trained to systematically inspect them, observing discharge summaries, medications used, laboratory test results, surgery records, nurses'notes and medical progress, to verify the presence of triggers in these medical records. Any indication of triggers starts an in-depth investigation into the AE and its severity. Then, afterwards, a physician performs a final analysis, legitimizing or not the results of the review of each of the medical records. It is noted that this tool uses five categories of harms, in accordance to the scale of the National Coordinating Council for Medication Error Reporting and Prevention, to classify the injury resulting from the $A E$, these being: temporary harm requiring intervention; temporary harm, with prolongation of hospitalization; permanent harm, damage that requires interventions to keep the patient alive; and death of the patient ${ }^{(34-36)}$.

Regarding the retrospective chart review, the main weakness exposed in the studies in this review and in a systematic review ${ }^{(37)}$ was due to the dependence on the records of health professionals and the quality of the documentation, as the inadequacy of the documents made it impossible, in some cases, to detect AEs. Also, only the AEs contemplated by the tracking tools were able to be identified. Finally, it was noted that the variability among reviewers (agreement) was often an obstacle, especially with regard to assessments of causality and preventability.

\section{Incidence, preventability, and main implications of AEs in hospitals}

A study carried out in a large hospital in England ${ }^{(19)}$ noted that $8.7 \%$ of 1,006 inpatients had at least one $A E$, of which $31 \%$ were preventable, confirming that AEs are common, serious, and potentially preventable sources of harm to patients. Of the AEs, 15\% caused injury/harm which lasted for six months or more, while 10\% contributed to the death of the individuals. The mean increase in hospital stay due to AEs was eight days.

The authors of a research carried out in Spain ${ }^{(20)}$ concluded that the number of patients that experienced AEs related to health care in 24 hospitals was relevant and similar to previous results from Canadian and Australian studies using comparable methods. The incidence of AEs directly related to hospital care was $8.4 \%$. The incidence density was $1.2 \mathrm{AE}$ per 100 patient-days, while the incidence of events classified as moderate and severe was $5.6 \mathrm{AEs}$ per 1,000 patient-days. In total, $42.8 \%$ of the AEs were considered preventable. Patients older than 65 years old had a higher frequency of AEs (12.4\%) compared to those below this age group (5.4\%). The most recurrent AEs were associated with medication (37.4\%) and with hospital infections (25\%). Approximately $30 \%$ of the AEs led to an increase in hospital stay.

A research carried out in 21 Dutch hospitals ${ }^{(22)}$ found that the reduction in the incidence, preventability, and deaths from potentially preventable AEs were substantial elements in improving patient safety. In short, one or more AEs were found in $5.7 \%$ of the hospitalizations, among which the preventability rate was $2.3 \%$. Of the total number of AEs, $12.8 \%$ resulted in permanent disability or contributed to death. The proportion and impact of AEs increased with advancing age, $50 \%$ of the AEs being related to surgical procedures. Of the hospital deaths, $10.7 \%$ experienced one AE, as preventable AEs occurred in $4.1 \%$ of the cases.

In a Brazilian study ${ }^{(21)}$ conducted in three teaching hospitals, the incidence of patients that experienced AEs was $7.6 \%$, and the preventability percentage was $66.7 \%$. It is important to emphasize that the proportion of preventable AEs was much higher in Brazilian hospitals than those found in other research studies. The incidence density was $0.8 \mathrm{AE}$ per $100 \mathrm{pa-}$ tient-days and, regarding classification, surgical AEs were the most common (35.2\%).

In Tunisia, the AE incidence rate in a university hospital was $10 \%$. Errors in surgical/invasive procedures and treatment 
were the most common AEs. Among the identified events, $60 \%$ were considered preventable and $21 \%$ caused the death of patients. The AE rates between age groups and genders were similar. It was estimated that the additional hospital stay associated with AEs was 570 days, using a significant portion of hospital resources ${ }^{(23)}$.

Another Spanish study carried out in a university hospital showed that the AE rate was $6.8 \%$, and that $63.3 \%$ were considered preventable. Among the AEs detected, $8.2 \%$ were linked to care, $14.3 \%$ to medication, $26.5 \%$ to hospital infections, $35.7 \%$ to technical problems in the procedures, $11.2 \%$ to diagnosis and, finally, $4.1 \%$ were associated with other practices. Approximately $50 \%$ of the AEs increased the length of hospital stay ${ }^{(24)}$.

A study conducted in 26 hospitals from developing country (Egypt, Jordan, Kenya, Morocco, South Africa, Sudan, Tunisia, and Yemen) $)^{(25)}$ found that $8.2 \%$ of the hospitalizations had at least one $\mathrm{AE}$, ranging from $2.5 \%$ to $18.4 \%$ among the countries investigated. Of these events, $83 \%$ were preventable, and $30 \%$ were associated with the death of the patients. In summary, the inadequate training and supervision of the care team and the infringement of policies and protocols favored the occurrence of most of the events.

The study that used the IHI-GTT to assess AEs in two large hospitals in Palestine ${ }^{(26)}$ described that one out of seven patients (14.2\%) suffered one or more AEs, of which 59.3\% were preventable. It was observed that $70.4 \%$ of the events resulted in temporary harm, thus prolonging hospitalization. Among all the AEs, a large portion was related to surgical procedures (27.5\%), while the remaining events were associated with pressure injury (2.3\%), medications (15.3\%), and deep venous thrombosis (14.3\%), which are potentially preventable.

After an investigation carried out in a private hospital in Chile ${ }^{(27)}$, it was reported that $6.2 \%$ of the patients experienced one or more AEs related to health care, with an incidence density of 3.46 AEs per 100 patient-days and a preventability rate of $67.6 \%$. The main procedures associated with AEs were the following: general care, such as pressure injuries and other consequences of prolonged immobility, burns, abrasions, bruises and fractures (32.4\%); medications (13.5\%); infections related to health care (10.8\%); and medical diagnosis (8.1\%). The mean increase in hospital stay due to AEs was 5.5 days, with hospital readmission in $8.11 \%$ of the cases.

According to a study carried out in 15 hospitals in the Catalonia region of Spain ${ }^{(28)}$, the $\mathrm{AE}$ rate in these institutions was $7.4 \%$. Of these cases, $43.5 \%$ represented preventable AEs. The investigation made it possible to state that AEs in hospitals in the western Spanish region were frequent and had a significant impact on morbidity and mortality, making it possible to identify priority sectors to concentrate quality and safety improvement actions in health care.

The results of the study from three hospitals in Portugal ${ }^{(29)}$ showed the need for epidemiological studies on the incidence and type of AEs. The main findings involved an AE incidence rate of $11.1 \%$, of which $53.2 \%$ were considered preventable. Most of the AEs were linked to surgical procedures (27\%), medication errors (18.3\%), and hospital infections (12.2\%), noting that $10.8 \%$ caused deaths. In $58.6 \%$ of the events, the length of hospital stay was increased by 10.7 days, on average.

The findings of the research carried out in four Iranian hospitals ${ }^{(30)}$ revealed that $7.3 \%$ of the inpatients had some AE during the hospitalization, while $3.7 \%$ of the patients were admitted as a result of a previous AE. Thus, $11.0 \%$ of the AEs affected $10.9 \%$ of the patients, since two individuals experienced more than one event. It was considered that $34.3 \%$ of the AEs were preventable, especially those related to adverse reactions to medications, postoperative infections, pressure injuries, and hospital infections.

A study carried out in eight hospitals in Ireland ${ }^{(31)}$ reported that the $\mathrm{AE}$ rate in hospitalizations was $10.3 \%$, of which $72.7 \%$ were assessed as preventable. A percentage of $9.9 \%$ caused permanent harm to patients, and $6.7 \%$ of the episodes resulted in deaths. In addition, it was calculated that the mean additional time in the hospital stay due to AEs was 6.1 days, representing an expense of $€ 5,550$ per event.

A limitation found in this review is the fact that the searches performed in the databases included only publications in Portuguese, English and Spanish, not including articles on the topic in languages other than those considered in the search.

\section{CONCLUSION}

This review provided a global overview regarding retrospective chart reviews in the assessment of AEs through the use of several data collection instruments, namely: HMPS, CAES, QAHCS and IHI-GTT. The selected studies showed differences in the $A E$ incidence and preventability rates, which ranged from $5.7 \%$ to $14.2 \%$, and from $31 \%$ to $83 \%$, respectively. Such heterogeneity found in the results can be justified by the divergences among the hospitals surveyed, the quality of hospital care provided, and the information recorded in the medical records, sample size, screening criteria for potential AEs and, finally, by the variation in the number of medical reviewers involved in the stage of assessing AEs and in the quality of the judgment of these professionals, especially with regard to the AE preventability rates. 
The magnitude of the results reinforces that the knowledge about the incidence and preventability of AEs should be assimilated as a first step towards improving patient safety and quality in health care, since it guides future interventions for the attenuation of specific AEs, especially those that need to be prioritized, and promotes a safety culture in health institutions, in addition to demonstrating, based on reliable data and solid information, that patient safety should not be seen as an expense, but as an investment.

\section{$\square$ REFERENCES}

1. Sartor GD, Silva BF, Masiero AV. Patient safety in large-sized hospitals: panorama and challenges. Cogitare Enferm. 2016;21(2):1-8. doi: https://doi. org/10.5380/ce.v21i2.45665

2. Duarte SCM, Stipp MAC, Silva MM, Oliveira FT. Adverse events and safety in nursing care. Rev Bras Enferm. 2015;68(1):144-54. doi: https://doi. org/10.1590/0034-7167.2015680120p

3. Brennan $T A$, Leape $L L$, Laird NM, Hebert $L$, Localio AR, Lawthers AG, et al. Incidence of adverse events and negligence in hospitalized patients - results of the Harvard Medical Practice Study I. N Engl J Med. 1991;324(6):370-6. doi: https://doi.org/10.1056/NEJM199102073240604

4. Runciman W, Hibbert P, Thomson R, Van Der Schaaf T, Sherman H, Lewalle $P$. Towards an international classification for patient safety: key concepts and terms. Int J Qual Health Care. 2009;21(1):18-26. doi: https://doi.org/10.1093/ intahc/mzn057

5. Moran KM, Harris IB, Valenta AL. Competencies for patient safety and quality improvement: a synthesis of recommendations in influential position papers. Jt Comm J Qual Patient Saf. 2016;42(4):162-9. doi: https://doi.org/10.1016/ s1553-7250(16)42020-9

6. Marchon SG, Mendes Junior WV. Patient safety in primary health care: a systematic review. Cad Saude Publica. 2014;30(9):1815-35. doi: https://doi. org/10.1590/0102-311X00114113

7. Elmontsri M, Almashrafi A, Banarsee R, Majeed A. Status of patient safety culture in Arab countries: a systematic review. BMJ Open. 2017;7(2):e013487. doi: https://doi.org/10.1136/bmjopen-2016-013487

8. van Melle MA, Zwart DLM, Poldervaart JM, Verkerk 0J, Langelaan M, van Stel $H F$, et al. Validity and reliability of a medical record review method identifying transitional patient safety incidents in merged primary and secondary care patients' records. BMJ Open. 2018;8(8):e018576. doi: https://doi.org/10.1136/ bmjopen-2017-018576

9. Howard IL, Bowen JM, Al Shaikh LAH, Mate KS, Owen RC, Williams DM. Development of a trigger tool to identify adverse events and harm in emergency medical services. Emerg Med J. 2017;34(6):391-7. doi: https://doi. org/10.1136/emermed-2016-205746

10. Patient safety is not a luxury [editorial]. Lancet. 2016;387(10024):1133. doi: https://doi.org/10.1016/S0140-6736(16)30003-4

11. Mendes W, Travassos C, Martins M, Noronha JC de. Revisão dos estudos de avaliação da ocorrência de eventos adversos em hospitais. Rev Bras Epidemiol. 2005;8(4):393-406. doi: https://doi.org/10.1590/S1415-790X2005000400008

12. Zhang E, Hung S-C, Wu C-H, Chen L-L, Tsai M-T, Lee W-H. Adverse event and error of unexpected life-threatening events within $24 \mathrm{~h}$ of emergency department admission. Am J Emerg Med. 2017;35(3):479-83. doi: https://doi. org/10.1016/j.ajem.2016.11.062
13. Ercole FF, Melo LS, Alcoforado CLGC. Integrative Review versus Systematic Review [editorial]. Rev Min Enferm - REME. 2014;18(1):12-14. doi: https://doi. org/10.5935/1415-2762.20140001

14. Mendes KDS, Silveira RCCP, Galvão CM. Revisão integrativa: método de pesquisa para a incorporação de evidências na saúde e na enfermagem. Texto Contexto Enferm. 2008;17(4):758-64. doi: https://doi.org/10.1590/ S0104-07072008000400018

15. Souza MT, Silva MD, Carvalho R. Integrative review: what is it? How to do it? Einstein. 2010;8(1):102-6. doi:https://doi.org/10.1590/s1679-45082010rw1134

16. Santos CMC, Pimenta CAM, Nobre MRC. The PICO strategy for the research question construction and evidence search. Rev Lat-Am Enfermagem. 2007;15(3):508-11. doi: https://doi.org/10.1590/50104-11692007000300023

17. Ursi ES, Galvão CM. Prevenção de lesões de pele no perioperatório: revisão integrativa da literatura. Rev Lat-Am Enfermagem. 2006;14(1):124-31. doi: https://doi.org/10.1590/S0104-11692006000100017

18. Melnyk BM, Fineout-Overholt E. Evidence-based practice in nursing and healthcare: a guide to best practice. 2nd ed. Philadelphia: Wolters Kluwer Health/Lippincott, Williams \& Wilkins; 2011.

19. Sari AB, Sheldon TA, Cracknell A, Turnbull A, Dobson Y, Grant C, et al. Extent, nature and consequences of adverse events: results of a retrospective casenote review in a large NHS hospital. Qual Saf Heal Care. 2007;16(6):434-9. doi: https://doi.org/10.1136/qshc.2006.021154

20. Aranaz-Andres JM, Aibar-Remon C, Vitaller-Murillo J, Ruiz-Lopez P, LimonRamirez R, Terol-Garcia $E$, et al. Incidence of adverse events related to health care in Spain: results of the Spanish National Study of Adverse Events. J Epidemiol Community Heal. 2008;62(12):1022-9. doi: https://doi.org/10.1136/ jech.2007.065227

21. Mendes W, Martins M, Rozenfeld S, Travassos C. The assessment of adverse events in hospitals in Brazil. Int J Qual Heal Care. 2009;21(4):279-84. doi: https://doi.org/10.1093/intqhe/mzp022

22. Zegers M, de Bruijne MC, Wagner C, Hoonhout LHF, Waaijman R, Smits M, et al. Adverse events and potentially preventable deaths in Dutch hospitals: results of a retrospective patient record review study. Qual Saf Heal Care. 2009;18(4):297302. doi: https://doi.org/10.1136/qshc.2007.025924

23. Letaief M, El Mhamdi S, El-Asady R, Siddiqi S, Abdullatif A. Adverse events in a Tunisian hospital: results of a retrospective cohort study. Int I Qual Heal Care. 2010;22(5):380-5. doi: https://doi.org/10.1093/intqho/mzq040

24. Lucas-Imbernón FJ, Aranaz-Andrés JM, Gea-Velázquez de Castro MT, GallardoMartínez D, Limón-Ramírez R, García-Fernández C. Plan de seguridad clínica del Complejo Hospitalario Universitario de Albacete (CHUA). Diagnóstico inicial: estudio de eventos adversos. Rev Calid Asist. 2012;27(4):189-96. doi: https:// doi.org/10.1016/j.cali.2011.10.005

25. Wilson RM, Michel P, Olsen S, Gibberd RW, Vincent C, El-Assady R, et al. Patient safety in developing countries: retrospective estimation of scale and nature of harm to patients in hospital. BMJ. 2012;344:e832. doi: https://doi.org/10.1136/ bmj.e832

26. Najjar S, Hamdan M, Euwema MC, Vleugels A, Sermeus W, Massoud R, et al. The Global Trigger Tool shows that one out of seven patients suffers harm in Palestinian hospitals: challenges for launching a strategic safety plan. Int I Qual Heal Care. 2013;25(6):6407. doi: https://doi.org/10.1093/intqhc/mzt066

27. Lancis-Sepúlveda ML, Asenjo-Araya C. Estudio de incidencia de eventos adversos en una clínica privada en Chile. Rev Calid Asist. 2014;29(2):78-83. doi: https://doi.org/10.1016/j.cali.2013.10.003 
28. Bañeres J, Orrego C, Navarro L, Casas L, Banqué M, Suñol R. Epidemiología de los eventos adversos hospitalarios en Catalunya: un primer paso para la mejora de la seguridad del paciente. Med Clin (Barc). 2014;143(Supl 1):3-10. doi: https://doi.org/10.1016/j.meddli.2014.07.005

29. Sousa P, Uva AS, Serranheira F, Nunes C, Leite ES. Estimating the incidence of adverse events in Portuguese hospitals: a contribution to improving quality and patient safety. BMC Health Serv Res. 2014;14(1):311. doi: https://doi. org/10.1186/1472-6963-14-311

30. Sari AA, Doshmangir L, Torabi F, Rashidian A, Sedaghat M, Ghomi R, et al. The incidence, nature and consequences of adverse events in Iranian hospitals. Arch Iran Med. 2015 [cited 2019 May 15];18(12):811-5. Available from: http://www. ams.ac.ir/AIM/NEWPUB/15/18/12/004.pdf

31. Rafter N, Hickey A, Conroy RM, Condell S, O'connor P, Vaughan D, et al. The Irish National Adverse Events Study (INAES): the frequency and nature of adverse events in Irish hospitals: a retrospective record review study. BMJ Qual Saf. 2017;26(2):111-9. doi: https://doi.org/10.1136/bmjqs-2015-004828

32. Wilson RM, Runciman WB, Gibberd RW, Harrison BT, Newby L, Hamilton JD. The quality in Australian Health Care Study. Med J Aust. 1995;163(9):458-71. doi: https://doi.org/10.5694/j.1326-5377.1995.tb124691.x

33. Baker GR, Norton PG, Flintoft V, Blais R, Brown A, Cox J, et al. The Canadian Adverse Events Study: the incidence of adverse events among hospital patients in Canada. CMAJ. 2004;170(11):1678-6. doi: https://doi.org/10.1503/ cmaj.1040498

\section{- Corresponding author:}

Ariane Cristina Barboza Zanetti

E-mail: arianezanetti@usp.br
34. Griffin FA, Resar RK. IHI Global Trigger Tool for Measuring Adverse Events. 2nd ed. Cambridge, MA: Institute for Healthcare Improvement; 2009 [cited 2019 May 15]. Available from: http://www.hi.org/resources/Pages/ IHIWhitePapers/IHIGlobalTriggerToolWhitePaper.aspx

35. Nilsson L, Borgstedt-Risberg M, Soop M, Nylén U, Ålenius C, Rutberg H. Incidence of adverse events in Sweden during 2013-2016: a cohort study describing the implementation of a national trigger tool. BMJ Open. 2018;8(3):e020833. doi: https://doi.org/10.1136/bmjopen-2017-020833

36. Pierdevara L, Ventura I, Eiras M, Gracias A, Silva C. An experience with the Global Trigger Tool for the study of adverse events in a medical ward. Rev Enferm Ref. 2016;IV(9):97-106. doi: https://doi.org/10.12707/RIV15078

37. Panagioti M, Khan K, Keers RN, Abuzour A, Phipps D, Kontopantelis E, et al. Prevalence, severity, and nature of preventable patient harm across medical care settings: systematic review and meta-analysis. BMJ. 2019;366:14185. doi: https://doi.org/10.1136/bmj.14185

\section{Acknowledgment}

The present paper was carried out with the support of the Coordination for the Improvement of Higher Education Personnel (Coordenação de Aperfeiçoamento de Pessoal de Nivel Superior, (APES) - Brazil - Financing Code 001.

\section{Editor-in-chief:}

Maria da Graça Oliveira Crossetti 